\title{
Produção de enzimas extracelulares por Ceratocystis spp.
}

\author{
Ana Carolina Firmino ${ }^{1}$, Edson Luiz Furtado ${ }^{1}$
}

${ }^{1}$ Departamento de Produção Vegetal/Defesa Fitossanitária, UNESP/FCA, CEP 18610-307, Botucatu, SP, Brasil.

*Autor para correspondência: Edson Luis Furtado (elfurtado@fca.unesp.br).

Data de chegada: 13/03/2014. Aceito para publicação em: 29/09/2014.

$10.1590 / 0100-5405 / 1986$

\section{RESUMO}

Firmino, A.C. Furtado, E.L. Produção de enzimas extracelulares por Ceratocystis spp. Summa Phytopathologica, v.40, n.4, p.371-374, 2014.

\begin{abstract}
O gênero Ceratocystis contempla diversas espécies distribuídas em vários lugares do mundo. No Brasil ocorrem relatos da existência de três espécies, sendo elas: C. cacaofunesta, C. paradoxa e C. fimbriata, sendo esta última relacionada a doença em culturas de importância econômica. O trabalho objetivou verificar, em meios de cultura específicos, a produção das enzimas extracelulares amilase, lipase, celulase, protease, lacase e lignina peroxidase e pectiliase (pectato-liase) por isolados de Ceratocystis sp. Foram usados 41 isolados: 3 de mangueira (Mangifera indica), 19 de eucalipto (Eucalyptus spp.), 15 de cacaueiro (Theobroma cacao), 2 de Teca (Tectona grandis) e 2 de atemóia
\end{abstract}

(Annona sp.). As colônias foram incubadas no escuro a $25^{\circ} \mathrm{C}$, com exceção do meio para detecção de pectinase que foi incubado sob fotoperíodo alternado. $\mathrm{O}$ delineamento experimental foi inteiramente casualizado com 4 repetições. A partir dos meios específicos foi possível detectar a produção de amilase, lacase e protease quase na totalidade dos isolados Ceratocystis sp. testados. Não foi observada a produção de celulase, lípase e pectatoliase. A produção da enzima lignina peroxidade foi detectada em pouca quantidade e em somente alguns isolados do fungo. Este perfil enzimático obtido da população do fungo pode auxiliar em futuros estudos relacionados com a caracterização deste.

Palavras-chave adicionais: caracterização, enzimas, fungo

\section{ABSTRACT}

Firmino, A.C. Furtado, E.L. Extracellular enzyme production by Ceratocystis spp. Summa Phytopathologica, v.40, n.4, p.371-374, 2014.

The genus Ceratocystis includes several species distributed over several parts of the world. In Brazil there are reports of the existence of three species: $C$. cacaofunesta, C. paradoxa and C. fimbriata, the latter being related to disease in crops of economic importance. This study aimed to determine, in specific culture media, the production of the extracellular enzymes amylase, lipase, cellulase, protease, laccase, lignin peroxidase and pectiliase (pectatelyase) for isolates of Ceratocystis spp. A total of 41 isolates were used: 3 from mango (Mangifera indica), 19 from eucalyptus (Eucalyptus spp.), 15 from cocoa (Theobroma cacao), 2 from Teak (Tectona grandis) and 2 from atemoya (Annona sp.). The colonies were incubated in the dark at $25^{\circ} \mathrm{C}$, except for the medium for pectinase detection which was incubated under alternating photoperiod. Experimental design was completely randomized with 4 replicates. The specific media allowed the detection of the production of amylase, laccase and protease for almost all tested isolates of Ceratocystis sp. Production of cellulase, lipase and pectatelyase was not observed. Production of the enzyme lignin peroxidase was detected in small amounts and in only a few isolates of the fungus. This enzymatic profile obtained from the fungus population may assist in future studies related to its characterization.

Additional keywords: characterization, enzymes, fungi

O gênero Ceratocystis contempla diversas espécies fungicas distribuídas em vários lugares do mundo. No Brasil há relatos de C. cacaofunesta, ocorrendo em cacaueiro, C. paradoxa, ocorrendo, principalmente, em cana de açúcar e palmeiras e o mais importante $C$. fimbriata, que atacada diversas espécies de plantas como acácia negra (Acacia mearnsii), eucalipto (Eucalyptus spp.), figo (Ficus carica), gmelina (Gmelina arborea), manga (Mangifera indica) e seringueira (Hevea brasiliensis).

Em plantas lenhosas, o fungo Ceratocystis é um típico patógeno de xilema (1), cujo sintoma característico é o escurecimento dos vasos do xilema. Normalmente uma planta infectada com este patógeno tem como primeiros sintomas a perda de coloração verde-escura da folhagem, seguida de murcha das folhas e conseqüentemente seca da planta.

Espécies de Ceratocystis estão fortemente associadas com insetos apesar de ainda não se conhecer os vetores específicos de $C$. fimbriata na América Latina. Árvores infectadas com o fungo Ceratocystis são freqüentemente atacadas por scolytideos (Coleoptera: Curculionidae: Scolytinae e Platypodinae).

No Brasil até meados de 1990, C. fimbriata era considerado problema somente em plantações de mangueira. Em cacaueiro, a murcha-de-Ceratocystis tem causado danos econômicos na cacauicultura do Brasil desde 2001 e em países vizinhos (7). Em plantas de eucalipto há relatos de talhões monoclonais que apresentavam mortalidade de plantas superior a $40 \%$.

Para o estabelecimento de um fungo em uma planta e o desenvolvimento da doença há a ocorrência de uma série de etapas de reconhecimento entre o patógeno e planta. Durante este reconhecimento, algumas exigências devem ser atendidas. Essas exigências implicam na ativação de várias vias metabólicas tanto do lado do patógeno quanto do lado do hospedeiro. As vias metabólicas envolvidas nestes processos estão ligadas a troca de sinais entre patógenos e hospedeiro. Estes sinais podem ser de natureza química ou física. Os sinais de natureza química por parte do patógeno envolvem as atividades de enzimas que podem 
exercerem diferentes funções, como por exemplo degradação da parede de células do hospedeiro, facilitando a penetração do fungo na planta (6) Entre os microrganismos fitopatogênicos, muitos produzem proteases extracelulares ativas que, em conjunto com outras enzimas como poligalacturonases, pectoliases e xilanases, exercem um importante papel na patogênese (10).

Diante do problema que o Ceratocystis vem causando em diferentes culturas e da importância que este patógeno vem tomando, o presente trabalho teve como objetivos caracterizar aspectos enzimáticos deste fungo coletados de diferentes hospedeiros.

Para este estudo foram utilizados 41 isolados: 3 de mangueira (Mangifera indica), 19 de eucalipto (Eucalyptus spp.), 15 de cacaueiro (Theobroma cacao), 2 de Teca (Tectona grandis) e 2 de atemóia (Annona sp.). Discos com $5 \mathrm{~mm}$ de diâmetro de meio MEA (2\% de Malte, 0,2\% de Extrato de levedura e 1\% de Agar) contendo estruturas do fungo foram retirados do bordo de colônias cultivadas por 14 dias no escuro sob temperatura de $25^{\circ} \mathrm{C} \pm 1$ e repicados individualmente para o centro de placas de Petri, contendo os meios específicos para detecção das enzimas. Os protocolos para detecção das atividades da pectinase, proteinase e lipase estão de acordo com a metodologia descrita por Hankin e Anagnostakis (4), os protocolos para atividades da lacase, lignina peroxidase, amilase e celulase foram realizados com como descrito por Firmino (2). Com exceção da enzima lacase, que foi avaliada através da atribuição de notas, todas as outras enzimas foram avaliadas através do cálculo de índice enzimático (diâmetro da colônia $(\mathrm{mm})$ / diâmetro do halo formado (mm)).

O delineamento experimental foi inteiramente casualizado com 4 repetições. Os dados obtidos foram submetidos à análise de variância e as médias das repetições dos isolados foram comparadas entre si para cada enzima por meio da aplicação do teste de Scott-Knott ao nível de $5 \%$ de probabilidade, através do programa Sisvar.

A partir dos meios específicos, foi possível detectar a produção de protease, lignina peroxidase, lacase e amilase quase na totalidade dos isolados de Ceratocystis spp. testados (Tabela 1). Foi detectada grande variação na produção das enzimas protease e lignina peroxidase nos isolados testados, sendo esta ultima comum em fungos que degradam madeira. As enzimas proteolíticas produzidas por microrganismos podem atuar na hidrólise de proteínas da membrana e da parede celular de plantas hospedeiras, facilitando a penetração e a infecção.
A maioria dos isolados que mostrou produção intensa da enzima lacase pertence aos isolados de Ceratocystis coletadas de cacau (C. cacaufunesta). Esta diferença na produção desta enzima pode auxiliar em futuros estudos relacionados com a caracterização deste fungo, vindo a ser uma ferramenta rápida para distinguir espécies de Ceratocystis de cacau de outras espécies deste fungo. Ademais, a constatação da produção de lignina peroxidase e lacase por Ceratocystis vem a ser muito importante, pois estas duas enzimas são as principais enzimas envolvidas na degradação da lignina (5). Estas enzimas são descritas como importantes para os microrganismos fitopatogênicos, pois é através destas que eles se tornam capazes de superar a resistência natural dos componentes da madeira, em especial a lignina, que é constituída por uma estrutura aromática complexa (3). A lacase vem ganhando importância devido à capacidade de catalisar a oxidação de fenóis e outros compostos aromáticos, sendo utilizadas em diversos processos, como remoção de lignina de polpas kraft em indústrias de papel e celulose, remoção de xenobióticos de cursos d'água, análise de drogas, remoção de compostos fenólicos de vinho, clarificação de corantes e efluentes, entre muitos outros, por apresentarem baixa especificidade por substratos.

Para a enzima amilase, não foi constatada variação significativa entre os isolados testados, exceto pelo isolado AFC07 que não produziu esta enzima. Alguns autores citam a presença de aglomerados de amido em plantas infectadas com Ceratocystis $(9,8)$, podendo, assim, a amilase do fungo também estar relacionada à patogenicidade.

Não foram observadas as produções de celulase, lipase e pectatoliase. A ausência da produção de pectato-liase não era esperada, pois, segundo a literatura, Ceratocystis spp. pode induzir tiloses em plantas hospedeiras (8), sendo que a formação destas tiloses é favorecida pela degradação da lamela média por meio de pectinases produzidas pelo patógeno (6). Assim pode haver duas hipóteses, a de que o protocolo utilizado não foi sensível o suficiente para detectar a produção desta enzima, ou que o fungo produz pectinase somente em contato com seu hospedeiro.

Contudo, com base nos dados obtidos, é possível concluir que houve produção de amilase, lacase e protease quase na totalidade dos isolados Ceratocystis sp. testados, mas que estes mesmos isolados não produziram celulase, lípase e pectatoliase e que a enzima lignina peroxidade foi detectada em pouca quantidade e em somente alguns isolados do fungo.

Tabela 1. Produção de enzimas extracelulares por isolados de Ceratocystis, em meios de cultura específicos.

\begin{tabular}{|c|c|c|c|c|c|c|c|c|}
\hline \multirow{2}{*}{\multicolumn{2}{|c|}{ Isolados/Hospedeiro }} & \multicolumn{7}{|c|}{ Enzimas Extracelulares ${ }^{3}$} \\
\hline & & \multirow{2}{*}{$\begin{array}{c}\text { Protease }^{1} \\
0,82 \mathrm{c}\end{array}$} & \multirow{2}{*}{$\begin{array}{c}\text { Lig. Peroxidase }^{1} \\
0 \mathrm{a}\end{array}$} & \multirow{2}{*}{$\begin{array}{c}\text { Amilase }^{\mathbf{1}} \\
1,00 \mathrm{a}\end{array}$} & \multirow{2}{*}{$\begin{array}{c}\text { Lacase }^{2} \\
+++\end{array}$} & \multirow{2}{*}{$\begin{array}{c}\text { Lipase }^{1} \\
0,00\end{array}$} & \multirow{2}{*}{$\begin{array}{c}\text { Celulase }^{1} \\
0,00\end{array}$} & \multirow{2}{*}{$\begin{array}{c}\text { Pectatoliase }^{1} \\
0,00\end{array}$} \\
\hline ACF1 & Manga & & & & & & & \\
\hline $\mathrm{ACF} 2$ & Manga & $0,87 \mathrm{c}$ & $0,88 \mathrm{~d}$ & $0,98 \mathrm{a}$ & + & 0,00 & 0,00 & 0,00 \\
\hline $\mathrm{ACF} 3$ & Manga & $0,86 \mathrm{c}$ & $0,93 \mathrm{e}$ & $1,00 \mathrm{a}$ & ++ & 0,00 & 0,00 & 0,00 \\
\hline $\mathrm{ACF} 4$ & Manga & $0,84 \mathrm{c}$ & $0,95 \mathrm{e}$ & $1,00 \mathrm{a}$ & ++ & 0,00 & 0,00 & 0,00 \\
\hline ACF5 & Cacau & $0,69 b$ & $0,81 \mathrm{c}$ & $0,98 \mathrm{a}$ & + & 0,00 & 0,00 & 0,00 \\
\hline ACF6 & Cacau & $0,83 \mathrm{c}$ & $0,72 b$ & $1,00 \mathrm{a}$ & +++ & 0,00 & 0,00 & 0,00 \\
\hline ACF7 & Cacau & $0,87 \mathrm{c}$ & $0,00 \mathrm{a}$ & $0,00 \mathrm{~b}$ & +++ & 0,00 & 0,00 & 0,00 \\
\hline $\mathrm{ACF} 8$ & Cacau & $0,78 b$ & $0,83 \mathrm{~d}$ & $0,94 \mathrm{a}$ & +++ & 0,00 & 0,00 & 0,00 \\
\hline ACF9 & Cacau & $0,98 \mathrm{~d}$ & $0,84 \mathrm{~d}$ & $1,00 \mathrm{a}$ & +++ & 0,00 & 0,00 & 0,00 \\
\hline ACF 10 & Cacau & $0,75 b$ & $0,78 \mathrm{c}$ & $1,00 \mathrm{a}$ & +++ & 0,00 & 0,00 & 0,00 \\
\hline ACF11 & Cacau & $0,75 b$ & $0,69 \mathrm{~b}$ & $1,00 \mathrm{a}$ & +++ & 0,00 & 0,00 & 0,00 \\
\hline ACF12 & Cacau & $0,75 b$ & $0,66 \mathrm{~b}$ & $0,94 \mathrm{a}$ & +++ & 0,00 & 0,00 & 0,00 \\
\hline ACF13 & Cacau & $0,76 \mathrm{~b}$ & $0 \mathrm{a}$ & $0,98 \mathrm{a}$ & +++ & 0,00 & 0,00 & 0,00 \\
\hline ACF14 & Cacau & $0 \mathrm{a}$ & $0,78 \mathrm{c}$ & $1,00 \mathrm{a}$ & +++ & 0,00 & 0,00 & 0,00 \\
\hline
\end{tabular}


Tabela 1. Produção de enzimas extracelulares por isolados de Ceratocystis, em meios de cultura específicos.

\begin{tabular}{|c|c|c|c|c|c|c|c|c|}
\hline & & & & & & & & Continuação \\
\hline ACF15 & Cacau & $0,80 \mathrm{c}$ & $0,77 \mathrm{c}$ & $1,00 \mathrm{a}$ & +++ & 0,00 & 0,00 & 0,00 \\
\hline ACF16 & Cacau & $0,76 \mathrm{~b}$ & $0,79 \mathrm{c}$ & $1,00 \mathrm{a}$ & +++ & 0,00 & 0,00 & 0,00 \\
\hline ACF17 & Cacau & $0,91 \mathrm{~d}$ & $0,90 \mathrm{e}$ & $1,00 \mathrm{a}$ & ++ & 0,00 & 0,00 & 0,00 \\
\hline ACF18 & Cacau & $0,83 \mathrm{c}$ & $0,78 \mathrm{c}$ & $1,00 \mathrm{a}$ & +++ & 0,00 & 0,00 & 0,00 \\
\hline ACF19 & Cacau & $0,78 b$ & $0,83 d$ & $0,94 a$ & +++ & 0,00 & 0,00 & 0,00 \\
\hline ACF20 & Cacau & $0,70 \mathrm{~b}$ & $0,83 \mathrm{~d}$ & $1,00 \mathrm{a}$ & ++ & 0,00 & 0,00 & 0,00 \\
\hline ACF21 & Cacau & $0,71 b$ & $0,83 \mathrm{~d}$ & $0,98 \mathrm{a}$ & +++ & 0,00 & 0,00 & 0,00 \\
\hline ACF22 & Cacau & $0,90 \mathrm{~d}$ & $0,85 \mathrm{~d}$ & $1,00 \mathrm{a}$ & +++ & 0,00 & 0,00 & 0,00 \\
\hline ACF23 & Atemóia & $1,00 \mathrm{~d}$ & $0,85 \mathrm{~d}$ & $1,00 \mathrm{a}$ & +++ & 0,00 & 0,00 & 0,00 \\
\hline ACF24 & Atemóia & $0,82 \mathrm{c}$ & $0,91 \mathrm{e}$ & $0,93 a$ & + & 0,00 & 0,00 & 0,00 \\
\hline ACF25 & Eucalipto & $0,83 \mathrm{c}$ & $0,80 \mathrm{c}$ & $0,95 \mathrm{a}$ & +++ & 0,00 & 0,00 & 0,00 \\
\hline ACF26 & Eucalipto & $1,00 \mathrm{~d}$ & $0,85 \mathrm{~d}$ & $1,00 \mathrm{a}$ & ++ & 0,00 & 0,00 & 0,00 \\
\hline ACF27 & Eucalipto & $0 \mathrm{a}$ & $0,85 \mathrm{~d}$ & $0,91 \mathrm{a}$ & ++ & 0,00 & 0,00 & 0,00 \\
\hline ACF28 & Eucalipto & $0,71 \mathrm{~b}$ & $0,90 \mathrm{e}$ & $1,00 \mathrm{a}$ & ++ & 0,00 & 0,00 & 0,00 \\
\hline ACF29 & Eucalipto & $0,80 \mathrm{~b}$ & $0,95 \mathrm{e}$ & $0,98 \mathrm{a}$ & ++ & 0,00 & 0,00 & 0,00 \\
\hline ACF30 & Eucalipto & $0,84 \mathrm{c}$ & $0,95 \mathrm{e}$ & $0,95 \mathrm{a}$ & ++ & 0,00 & 0,00 & 0,00 \\
\hline ACF31 & Eucalipto & $0,88 \mathrm{c}$ & $0,94 \mathrm{e}$ & $0,95 \mathrm{a}$ & ++ & 0,00 & 0,00 & 0,00 \\
\hline ACF32 & Eucalipto & $0,82 \mathrm{c}$ & $0 \mathrm{a}$ & $0,96 \mathrm{a}$ & +++ & 0,00 & 0,00 & 0,00 \\
\hline ACF33 & Eucalipto & $0,85 \mathrm{c}$ & $0,79 \mathrm{c}$ & $0,95 \mathrm{a}$ & ++ & 0,00 & 0,00 & 0,00 \\
\hline ACF34 & Eucalipto & $0,84 \mathrm{c}$ & $0,77 \mathrm{c}$ & $0,95 \mathrm{a}$ & ++ & 0,00 & 0,00 & 0,00 \\
\hline ACF35 & Eucalipto & $0,88 \mathrm{c}$ & $0,77 \mathrm{c}$ & $0,96 \mathrm{a}$ & ++ & 0,00 & 0,00 & 0,00 \\
\hline ACF36 & Eucalipto & $0 \mathrm{a}$ & $0,79 \mathrm{c}$ & $0,94 \mathrm{a}$ & +++ & 0,00 & 0,00 & 0,00 \\
\hline ACF37 & Eucalipto & $0,99 d$ & $0,83 \mathrm{~d}$ & $1,00 \mathrm{a}$ & +++ & 0,00 & 0,00 & 0,00 \\
\hline ACF38 & Eucalipto & $0,78 b$ & $0,83 \mathrm{~d}$ & $1,00 \mathrm{a}$ & + & 0,00 & 0,00 & 0,00 \\
\hline ACF39 & Eucalipto & $1,00 \mathrm{~d}$ & $0,77 \mathrm{c}$ & $1,00 \mathrm{a}$ & ++ & 0,00 & 0,00 & 0,00 \\
\hline ACF40 & Eucalipto & $0,79 b$ & $0,86 \mathrm{~d}$ & $0,90 \mathrm{a}$ & + & 0,00 & 0,00 & 0,00 \\
\hline ACF41 & Eucalipto & $0,80 \mathrm{~b}$ & $0,83 \mathrm{~d}$ & $1,00 \mathrm{a}$ & + & 0,00 & 0,00 & 0,00 \\
\hline ACF42 & Eucalipto & $0,78 b$ & $0,82 \mathrm{~d}$ & $1,00 \mathrm{a}$ & + & 0,00 & 0,00 & 0,00 \\
\hline ACF43 & Eucalipto & $0,79 \mathrm{~b}$ & $0,83 \mathrm{~d}$ & $1,00 \mathrm{a}$ & + & 0,00 & 0,00 & 0,00 \\
\hline ACF44 & Eucalipto & $0,81 \mathrm{c}$ & $0 \mathrm{a}$ & $1,00 \mathrm{a}$ & ++ & 0,00 & 0,00 & 0,00 \\
\hline ACF45 & Eucalipto & $0,76 \mathrm{~b}$ & $0,86 \mathrm{~d}$ & $0,96 a$ & + & 0,00 & 0,00 & 0,00 \\
\hline ACF46 & Eucalipto & $1,07 d$ & $0 \mathrm{a}$ & $0,95 \mathrm{a}$ & ++ & 0,00 & 0,00 & 0,00 \\
\hline ACF47 & Eucalipto & $1,00 \mathrm{~d}$ & $0 \mathrm{a}$ & $1,00 \mathrm{a}$ & ++ & 0,00 & 0,00 & 0,00 \\
\hline ACF48 & Eucalipto & $0,80 \mathrm{c}$ & $0 \mathrm{a}$ & $0,96 a$ & ++ & 0,00 & 0,00 & 0,00 \\
\hline ACF49 & Eucalipto & $0,82 \mathrm{~b}$ & $0,87 \mathrm{~d}$ & $0,96 a$ & ++ & 0,00 & 0,00 & 0,00 \\
\hline ACF50 & Teca & $1,00 \mathrm{~d}$ & $0,85 \mathrm{~d}$ & $1,00 \mathrm{a}$ & ++ & 0,00 & 0,00 & 0,00 \\
\hline ACF51 & Teca & $1,00 \mathrm{~d}$ & $0,80 \mathrm{c}$ & $0,98 \mathrm{a}$ & ++ & 0,00 & 0,00 & 0,00 \\
\hline ACF52 & Eucalipto & $0,96 \mathrm{~d}$ & $1,00 \mathrm{f}$ & $0,98 \mathrm{a}$ & + & 0,00 & 0,00 & 0,00 \\
\hline ACF53 & Eucalipto & $0 \mathrm{a}$ & $0,92 \mathrm{e}$ & $1,00 \mathrm{a}$ & ++ & 0,00 & 0,00 & 0,00 \\
\hline ACF54 & Eucalipto & $0 \mathrm{a}$ & $0,98 \mathrm{f}$ & $1,00 \mathrm{a}$ & +++ & 0,00 & 0,00 & 0,00 \\
\hline ACF55 & Eucalipto & $0,75 b$ & $0,86 \mathrm{~d}$ & $0,91 \mathrm{a}$ & ++ & 0,00 & 0,00 & 0,00 \\
\hline
\end{tabular}

1: Resultados obtidos a partir do cálculo do Índice enzimático (diâmetro da colônia ( $\mathrm{mm}$ ) / diâmetro do halo formado (mm). Os isolados com maior índice são os que possuem menor atividade enzimática; 2: +++ (intensa); ++ (moderada); + (fraca) e - (ausência de alteração de cor no meio de cultura); 3: Médias seguidas de mesma letra minúscula na coluna não diferem significativamente, segundo teste de Scott-Knott a $5 \%$ de probabilidade.

\section{AGRADECIMENTOS}

Os autores agradecem a FAPESP (2011/05710-0) e ao CNPq pelo apoio financeiro. A Dra. Stela Dalva Vieira Midlej Silva e a Dra. Margarida Fumiko Ito. Ao IAC, CEPLAC e as empresas Suzano Papel e Velulose, V\&M e Fibria.

\section{REFERÊNCIAS BIBLIOGRÁFICAS}

1.Baker, C. J.; Harrington, T. C. Ceratocystis fimbriata. In: Crop protection compendium. Kew: CABI Publishing, 2004.

2.Firmino, A. C. Caracterização de isolados de Ceratocystis sp., avaliação de resistência clonal de eucalipto e sensibilidade deste fungo a diferentes fungicidas. 2011. 105 f. Tese (Doutorado em Agronomia/Proteção de Plantas)-Faculdade de Ciências Agronômicas, Universidade Estadual Paulista, Botucatu, 2011.
3.Giese, E.G.; Covizzi, L.G.; Dekker,R.F.H.; Barbosa, A.M. Influência de Tween na produção de lacases constitutivas e indutivas pelo Botryosphaeria sp. Acta Scientiarum: biological sciences, Maringá, v. 26, p. 463-470, 2004.

4.Hankin, L.; Anagnostakis, S. L. The use of solid média for detection of enzyme production by fungi. Mycologia, Lancaster, v. 67, p. 597-607, 1975.

5.Leonowicz, A.; Cho, N.S.; Luterek, J.; Wilkolazka, A.; Wojtas-Wasilewska M.; Matuszewska, A.; Hofrichter, M.; Wesenberg, D.; Rogalski, J. Fungal laccase: properties and activity on lignin. Journal Basic Microbiology, Berlin, v. 41, p. 185- 227, 2001.

6.Pascholati, S.F.; Leite, B.; Stangarlin, J.R.; Cia, P. Interação planta-patógeno: fisiologia, bioquímica e biologia molecular. Piracicaba: Fealq, 2008. v. 1, 627 p.

7.Sanches, C. L. G. Murcha-de-ceratocystis (Ceratocystis cacaofunesta) no sul da Bahia: metodologia para seleção de genótipos de cacaueiro resistentes e estudos preliminares descritivos do patógeno. 2007. 55 f. Dissertação (Mestrado em Produção Vegetal)-Universidade Estadual de Santa Cruz, Ilhéus, 2007.

8.Santos, R.M.F.; Silva, S. D. V. M.; Sena, K.; Micheli, F.; Gramacho, K. P. Kinetics and Histopathology of the Cacao-Ceratocystis cacaofunesta 
Interaction. Tropical Plant Biology, v.6, p. 37-45, 2013.

9.Tumura, K. G. Avaliação de resistência, análise epidemiológica, distribuição espacial e caracterização anatômica da madeira de clones de Eucalyptus sp. infectados por Ceratocystis fimbriata Ellis. Et Halsted. 2011. 50 f. Dissertação (Mestrado em Ciências Florestais)-
-Faculdade de Ciências Agronômicas, Universidade Estadual Paulista, Botucatu, 2011.

10. Valueva, T. A.; Mosolov, V. V. Role of inhibitors of proteolytic enzymes in plant defense against phytopathogenic microorganisms. Biochemistry, New York, v. 69, n. 1, p. 1305-1309, 2004 